\title{
Commemorating the 50th Anniversary of Korean Society of Nursing Science and Contemplating Direction to Move Forward
}

\author{
Cho, Kyung-Sook ${ }^{(1)}$ \\ College of Nursing, Gachon University · President of Korean Society of Nursing Science, Incheon, Korea
}

The World Health Organization has designated 2020 as the "International Year of the Nurse and Midwife." We are celebrating the 50th anniversary of our Korean Society of Nursing Science (KSNS) during this special year, which is also being celebrated across the world as the bicentenary of Florence Nightingale, the founder of modern nursing. The events and celebrations that were being planned for months have now been confronted with the new rules about social distancing and quarantine, necessitated by the COVID-19 situation. Although COVID-19 restricts getting together; it has brought attention to the real work and worth of nurses, in ways that no media campaigns and public relations initiatives ever could [1]. Nightingale was a strong advocate for infection control [2] and had always recommended, "Every nurse ought to be careful to wash her hands very frequently during the day." Like Nightingale, who saved the lives of numerous soldiers using statistics - a state-of-the-art science-at the time of the Crimean War, nurses as front-line staff workers are the best role models in the present troubled times of the COVID-19 pandemic.

KSNS started with 264 members in 1970, and has now grown into an academic society with 5,400 members [3] and two Science Citation Index Expanded journals: Journal of Korean Academy of Nursing (JKAN) and Asian Nursing Research (ANR) [4]. To keep pace with the social as well as medical changes brought about by scientific technology, KSNS should prepare a new paradigm to face its upcoming future and suggest a specific vision that would meet its needs and future requirements.

By 2050, the world will be home to 10 billion people, out of which, two in five will be aged 60 years or over. This combination of population growth and demographic changes will seriously accelerate the challenges that we will face for the delivery of health and healthcare, particularly since the global healthcare spend is projected to reach $13 \%$ of GDP in the OECD countries by 2050 [5].

In terms of health care, social and economic burdens are a central concern owing to an ultra-aged society and an increase in complex diseases. The answer to this concern lies partly in the ability of families and communities, as well as the modern social, political, economic, and health service delivery systems to provide optimal support to older persons [6]. In response to chronic diseases that come with a rapidly aging population, the Republic of Korea is committed to promoting preventative health measures [7]. Given that primary health care, self-care abilities, and medical-welfare linkages are important, the proportion of nursing care is increasing in the medical policy.

The fourth industrial revolution has ushered in information and communication technology applications along with service innovations represented by precision medicine, customized prevention and treatment, and data science. The new technology provides an opportunity to better understand people and health, and is expected to enhance the ultimate value of health promotion and the

Address reprint requests to : Cho, Kyung-Sook

College of Nursing, Gachon University · President of Korean Society of Nursing Science, 19 Hambakmoe-ro, Yeonsu-gu, Incheon 21936, Korea

Tel: +82-32-820-4208 Fax: +82-32-820-4201Ｅ-mail: kscho2265@gachon. ac. kr

Received: September 26, 2020 Revised: September 28, 2020 Accepted: September 28, 2020 Published online October 31, 2020

This is an Open Access article distributed under the terms of the Creative Commons Attribution NoDerivs License. (http://creativecommons. org/licenses/by-nd/4. 0)

If the original work is properly cited and retained without any modification or reproduction, it can be used and re-distributed in any format and medium. 
quality of life. Infectious diseases like COVID-19, which are currently a threat to the world, are bringing about changes in the health care industry, ranging from face-to-face treatment to telemedicine and electronic prescriptions [8].

Examining KSNS's history over the past 50 years, its main research topic in the 1970s was birth control and family planning, one of the characteristics of developing countries and a social issue. In the 1980s, its mission was the development of nursing concepts, theories, and philosophies, to extend its disciplinary boundary. In the 1990s, its mission was to progress into becoming an academic society with a predominance of female healthcare professionals. In the 2000s, its nursing scholars' undertaking was to expand KSNS's frontiers to the level of global standards. Lastly, in the 2010s, the qualitative and quantitative improvements in KSNS and JKAN were expected to make its future even more prosperous [4].

Is KSNS focused and prepared for the next 50 years?

To carry on KSNS's development, we have conducted mediation research for linking new knowledge and effective interventions to practical work; used data science and informatics tools necessary for precision medicine in the fourth industrial revolution; and introduced the latest practical and innovative research methodologies such as bio-behavioral research for assessing changes in lifestyle and quality of life [9].

KSNS has a 5-year plan to support academic and educational activities so that researchers can think in new and creative ways to explore unresolved problems as well as conduct performance-based research having core contents as follows.

First, to spread nursing knowledge, we shall establish a data bank to accumulate research and education materials, so that researchers can have easy online access for activating the academic data network. Additionally, we shall strengthen global scholar networks such as the International Council of Nurses, Sigma Theta Tau, and the East Asian Forum of Nursing Scholars for facilitating academic exchange and improving the international influence of our journals-JKAN and ANR.

Second, as an investment for future nursing scientists, we shall promote educational projects for research training and career development. Computers are important but they are likely to be effective only when well operated. Therefore, to complete the link, we are trying to provide career development opportunities to new and middle-level researchers, ranging from pre and post-doctoral fellowships. As one of the axes of the medical field, nursing science needs to be differentiated from the talent training programs organized by the government, universities, research institutes, and medical institutions, in the past. Furthermore, it can provide opportunities for interdisciplinary collaboration required for convergence training, as well as promote the establishment of an institutional bioethics committee in our society for researchers with insufficient research support conditions.

Third, for responding to the demands of the people and the health care system, as well as improving the ultimate value of health promotion and quality of life, we intend to promote the establishment of a policy development and research institute. During the past 50 years, we have prepared basic financial, material, and human infrastructure. Now is the time for us to reflect on KSNS's mission and develop policies that will help people to know about nursing and its allied activities. Support from people will provide us with opportunities to become the Chief Executive Officers in many medical institutions.

Lastly, we address our future nursing scholars, nurses, and nursing students. If we have planned the future, it is you who will actually make it happen. Never forget that a small step can make a huge difference. Think and constantly challenge so that you can expand your current nursing role, and expand the world of nursing to start-ups. In whatever you do, remember that you are working for the people's health. Find the change that you can make, and live such a life. Your efforts will change the future of nursing. We hope that young nursing talents in the KSNS will be able to unleash their creative competencies, communicate with society, and build their growth experiences.

The next half century will bring new challenges and demands that we have never experienced before. KSNS will be ready to meet these challenges with more proactive and innovative measures. We shall always work for the health of the people, remembering that "Nursing is our vision and calling," and that it contributes to the promotion of national health.

\section{CONFLICTS OF INTEREST}

The authors declared no conflict of interest. 


\section{REFERENCES}

1. D'Antonio P. Overview and summary: The 200th birthday of Florence Nightingale: Celebrating the history of nursing. The Online Journal of Issues in Nursing. 2020. doi: 10.3912/OJIN. Vol25No02ManOS.

2. Vawn Himmelsbach. Celebrating Nightingale [Internet]. Toronto: Toronto Star; c2020 [cited 2020 Sep 23]. Available from: https://nightingale2020.ca/.

3. Korean Society of Nursing Sciences. Korean Society of Nursing Sciences [Internet]. Seoul: Korean Society of Nursing Science; c2011 [cited 2020 Sep 22]. Available from: https://www.kan. or.kr/content/about/intro.php.

4. Kim JI, Suh EE, Song JE, Im Y, Park JH, Yu S, et al. Development of caring as a human science: 50 years of history of the Korean Society of Nursing Science. Journal of Korean Academy of Nursing. 2020;50(3):313-332.

https://doi.org/10.4040/jkan.20142

5. World Economic Forum. Insight report: Health and healthcare in the Fourth Industrial Revolution Global Future Council on the Future of Health and Healthcare 2016-2018 [Internet]. Geneva: World Economic Forum; c2019 [cited 2020 Sep 23]. Available from: http://www3.weforum.org/docs/WEF__Shaping_
the_Future_of_Health_Council_Report.pdf.

6. National Research Council (US) Panel on a Research Agenda and New Data for an Aging World. Preparing for an aging world: The case for cross-national research. In: National Research Council (US) Panel on a Research Agenda and New Data for an Aging World, editors. The Health of Aging Populations [Internet]. Washington (DC): National Academies Press (US); c2001 [cited 2020 Sep 23]. Available from: https:// www.ncbi.nlm.nih.gov/books/NBK98373/.

7. Ministry of Health and Welfare (MOHW). Challenges and tasks ahead [Internet]. Sejong: Ministry of Health and Welfare; 2020 Sep 23]. Available from: https://www.mohw.go.kr/eng/pl/ p10103.jsp?PAR_MENU_ID $=1003 \&$ MENU_ID $=100326$.

8. Kwon S. Telemedicine in the era of post-COVID-19 [Internet]. Seoul: The Korea Herald; c2020 [cited 2020 Sep 23]. Available from: http://www.koreaherald.com/view. php?ud=20200731000252.

9. Yu S, Kim JI, Park JH, Jang SJ, Suh EE, Song JE, et al. Analysis of research topics and trends in the Journal of Korean Academy of Nursing to improve its international influence. Journal of Korean Academy of Nursing. 2020;50(4):501-512. https://doi.org/10.4040/jkan.20167 